Voix et Images

vo1xetimages

\title{
"Vous vous rendez compte, n'est-ce pas, qu'une moitié ou plus des chefs-d'oeuvres [sic] de la littérature française sont interdits aux catholiques obéissants? » : un témoignage majeur de Louis Dantin
}

\section{Richard Giguère}

Volume 23, numéro 2 (68), hiver 1998

La censure 1920-1960

URI : https://id.erudit.org/iderudit/201362ar

DOI : https://doi.org/10.7202/201362ar

Aller au sommaire du numéro

Éditeur(s)

Université du Québec à Montréal

ISSN

0318-9201 (imprimé)

1705-933X (numérique)

Découvrir la revue

\section{Citer cet article}

Giguère, R. (1998). « Vous vous rendez compte, n’est-ce pas, qu’une moitié ou plus des chefs-d'oeuvres [sic] de la littérature française sont interdits aux catholiques obéissants? » : un témoignage majeur de Louis Dantin. Voix et Images, 23(2), 224-228. https://doi.org/10.7202/201362ar 


\section{«Vous vous rendez compte, n'est-ce pas, qu'une moitié ou plus des chefs- d'œuvres [sic] de la littérature française sont interdits aux catholiques obéissants? » : un témoignage majeur de Louis Dantin}

\section{Présentation de Richard Giguère, Université de Sherbrooke}

La correspondance d'Alfred DesRochers avec Louis Dantin s'échelonne de 1928 à 1939 et compte en tout 230 lettres (106 lettres de DesRochers à Dantin et 124 lettres dans le sens inverse). C'est l'une des plus riches correspondances d'écrivains de l'entre-deux-guerres ${ }^{1}$, tenue par un poète et un critique qui échangent par ailleurs des milliers de lettres avec une cinquantaine d'autres écrivains et écrivaines (en particulier des poètes), des critiques littéraires, des journalistes, des éditeurs, des membres du clergé, etc. À l'automne 1928, Alfred DesRochers, journaliste à La Tribune de Sherbrooke, apprend d'une collègue journaliste, Jovette Bernier, elle-même poète, qu'elle a commencé une correspondance avec Louis Dantin, pseudonyme d'Eugène Seers, exilé en Nouvelle-Angleterre (Cambridge, Massachusetts) depuis qu'il a quitté en 1903 la communauté des Pères du Très-Saint-Sacrement de Montréal. Comme Louis Dantin est le critique littéraire le plus admiré et le plus respecté par la nouvelle génération d'écrivains des années vingt, DesRochers lui envoie un exemplaire de son premier recueil, L'offrande aux vierges folles ${ }^{2}$, le 3 décembre 1928, et lui soumettra par la suite, au fur et à mesure de leur écriture; tous les poèmes rassemblés dans Á l'ombre de l'Orford ${ }^{3}$, en 1930. C'est ainsi que Louis Dantin, qui pourrait être le père d'Alfred DesRochers ( 64 ans contre 28 ans en 1929), devient le mentor du jeune poète.

1. Voir Voix et Images, "Les correspondants littéraires d'Alfred Desrochers "; $\mathrm{n}^{\circ} 46$, automne 1990, dossier p. 6-78.

2. Alfred DesRochers, Loffrande aux vienges folles, Sherbrooke, s.e., 1928.

3. Id. A lombre de lorford, Montreal, Librairie d Action canadienne-française, 1930. 
Le 25 décembre 1929, après un an d'une correspondance assidue entre les deux écrivains (40 lettres pour cette seule année), Dantin, voulant remercier le poète de Sherbrooke qui s'apprête à publier sur les presses de La Tribune une édition hors commerce et à tirage limité de son poème "Chanson javanaise", offre de hii donner un exemplaire soit de l'œuvre poétique de François Villon, soit de l'œuvre de Rabelais, soit des Confessions de Jean-Jacques Rousseau, tous des livres tìrés de sa bibliothèque personnelle. Le critique vante en particulier l'intérêt des Confessions, "un des livres les plus extraordinaires que la littérature ait produits ${ }^{4}$. Or DesRochers, dans sa réponse du 26 décembre, le remercie de sa générosité, mais explique qu'il ne peut accepter le titre de Rousseau parce qu'il se trouve dans l'Index de l'abbé Bethléem. Dantin est sans doute à la fois surpris et déçu par la réaction de son correspondant, car il a déjà prêté à Jovette Bernier, en avril 1929, les Contes de Voltaire (également inscrits à l'Index) et celle-ci "n'a pas battu d'une paupière ${ }^{5}$. Après trois jours de réflexion, le 29 décembre 1929, Louis Dantin écrit une lettre de deux feuillets ${ }^{6}$ (huit pages remplies de sa fine écriture) qui constitue une formidable leçon de liberté de pensée et d'indépendance intellectuelle à son jeune disciple représentant, avec quelques autres écrivains de sa génération, la relève de la littérature québécoise de son époque.

4 ANQ-S, Fonds Alfrect-DesRochers.

5. lbid.

6. Ibid 
Cambridge, 29 décembre 1929

Cher Mr. DesRochers,

Votre lettre m'arrive dans les derniers jours de l'an 1929, et me donne l'occasion de vous faire mes souhaits de santé, paix intime et succès, littéraire et autres, pour la nouvelle année. Je suis heureux d'apprendre que vous avez déjà un nouveau livre sur le métier, fait cette fois d'études critiques, et j’aurai grand intérêt à le parcourir, après qu'il aura conquis, comme j'espère, le prix que vous ambitionnez. Je l'aurais très volontiers, je vous assure, examiné d'avance; mais vous n'en êtes plus au point d'avoir besoin d'aide extérieure, et vos jugements littéraires auront, j'en suis sûr, toute la sûreté et la pondération voulues. Je n'en dirais pas autant de ce bien sympathique Rosaire Dion, dont le talent en est encore au stage d'incubation, et que je tâche de guider le mieux que je puis, ne lui ménageant pas des sévérités qui en blesseraient un autre, mais qu'il accepte avec une admirable modestie. Il est très regrettable que des soidisant juges de lettres comme Henri d'Arles aient encouragé ce jeune homme à publier un livre entièrement prématuré et qui n'a pu que nuire à sa réputation future. Je lui ai dit n'avoir trouvé dans tout le volume qu'une demi-douzaine de morceaux qui eussent valu d'être imprimés, après remaniement considérable! Il m'a depuis, envoyé d'autres pièces où le progrès est très visible, et je ne le dissuade nullement de continuer à écrire. Il a tous les éléments intimes de la poésie, tout ce qui lui manque; c'est l'expérience du langage, et il a déjà bien du mérite d'avoir acquis celle qu'il possède. Je vous dis ceci à son sujet, parce qu'il est, je crois, votre grand ami...

Votre étude physionomique sur ma binette m'a amusé, mais, comme toutes les conclusions de ces demi-sciences, n'a touché le but qu'en partie. Vous êtes tombé passablement juste sur mon "sens d'ironie"; mais mes "qualités viriles" ne me paraissent pas aussi indubitables. J'ai toujours cru avoir été loti de plus de traits féminins que d'autres. Je veux dire qu'en fait d'énergie, d'instinct combatif, de force de volonté, de goût pour les prouesses physiques, je me sens au-dessous de beaucoup de ces demoiselles. Et mes dispositions mentales vont vers la douceur, la pitié, la tolérance, vers une sorte de tendresse universelle qu'on associe (bien souvent à tort) avec le coeur féminin... Il n'y a qu'un seul point sur lequel je me suis senti toute ma vie aussi mâle que possible: c'est dans la passion jalouse de ma liberté (d'ailleurs aussi de celle des autres). Aucune tyrannie, 
ouverte ou sournoise, n'a de chance de me subjuguer, qu'elle prétende enfermer mon esprit, mon cour ou mon corps. Je lui échappe soit par la lutte ouverte, soit par une patience obstinée qui la déroute. Et la mesure de mes attachements, ou de mes haines pour les théories dogmatiques, sociales ou autres, c'est celle dans laquelle elles protègent ou détruisent la liberté humaine. J'ai quitté l'Église parce qu'elle est, à mon sens, la plus grande force d'oppression qui pèse sur les droits de l'esprit, sur les instincts de la nature, sur l'évolution normale de l'humanité; et j'ai le sens, depuis que j'en suis hors, d'être sorti d'un donjon, d'avoir recouvré la faculté de respirer et de me mouvoir... Je subirais toutes les misères et toutes les avanies que je croirais encore avoir gagné à secouer ce joug, qui est très loin, d'ailleurs, d'être celui du Christ... Et sans doute, je respecte ce que leur conscience dicte à d'autres. Il ne me viendrait pas l'idée, par exemple, de me moquer de vous parce que vous avez scrupule à lire les Confessions de Jean-Jacques. Mais je puis bien, avec cela, haür l'obscurantisme qui vous le défend. Et je me demande comment, dans le domaine de l'art littéraire, un esprit peut jamais atteindre à son complet développement, enserré dans ces bornes étouffantes. Il faut sûrement plus que du génie pour pouvoir siisoler ainsi de toute la tradition des siècles. Vous vous rendez bien compte, n'est-ce pas, qu'une moitié ou plus des chefsd'œuvres de la littérature française sont interdits aux catholiques obéissants? Vous ne pouvez lire ni les Essais de Montaigne, ni L'esprit des lois, ni les Lettres persanes de Montesquieu, ni rien de Rousseau, de Voltaire, de Diderot, de d'Alembert, de Marmontel (il ne reste plus que Fréron et l'abbé Delille). Vous ne pouvez même pas lire les Mêditations de Descartes! ni les Provinciales de Pascal! Les Contes de La Fontaine sont interdits (pas ceux de Boccace et de l'Arétin par exemple, qui faisaient les délices de Léon X). Pour des époques plus proches, on reste abasourdi de voir à quoi il faut fermer les yeux. On ne peut lire Notre-Dame de Paris, Les misérables, Jocelyn, Le voyage en Orient. On ne peut rien lire (imaginez-vous!) d'Alexandre Dumas père et fils, ni de Georges Sand, ni de Sue, ni de Soulié, ni de Stendhal, ni de Sterne. Et dire que Maupassant y échappe, le chançard! On ne peut rien lire de Balzac, ni de Zola! On doit ignorer Madame Bovary de Flaubert! Lamennais, Quinet, Michelet, Sainte-Beuve (pour son Port-Royal), Gioberti, Renan. (même pour l'Histoire des langues sémitiques), tous hors la loi!... Croyez-vous vraiment qu'on puisse se passer de toute cette éducation intellectuelie, et devenir un écrivain? Sans compter qu'en dehors de ces interdictions nominales, l'Index a des défenses englobant "tous les livres, quels qu'ils soient, contraires aux mours, ou attaquant les dogmes ou l'Église". Et les confesseurs sont là pour "compléter. dans le détail ce que l'Index a omis... N'y a-t-il pas eu des prêtres zélés courant, tout récemment, les librairies de Québec pour faire enlever des vitrines L'bomme qui va de Harvey? Et l'on se demande pourquoi la littérature canadienne reste étroite, mesquine et médiocre! Mais mon cher ami, pour ce passage du "lit triste "de votre livre, qui est peutetre sa plus 
originale et plus belle trouvaille, vous êtes vous-même menacé dè l'Index local!... Non, il faut reconnaître ce qui est l'évidence même: l'Église, par son esprit statique et par ses restrictions sans mesure, se pose en ennemie de toute liberté, de toute originalité littéraires. En s'écartant de ses routines, on s'écarte, selon elle, de la foi, de la morale, définies, bien entendu, et expliquées à sa façon. Elle ne veut même pas qu'on puisse savoir ce qui se pense, ce qui se dit en dehors d'elle. Elle ne veut pas qu'on aime, qu'on cherche, la vérité, la beauté pour elles-mêmes: il faut qu'on les trouve comme on peut dans les cercles qu'elle leur trace d'avance. Et si ce n'est pas là réduire en esclavage l'intelligence humaine, je ne sais ce qu'esclavage veut dire... Mais c'est là, naturellement, une opinion à moi que personne n'est tenu de partager. Et je respecte, jadmire même quiconque, croyant à l'Église et à son autorité, se fait un devoir de lui obéir. Être logique avec sa propre conscience, c'est, en somme, la moralité, lhonneteté pratique pour chaque être individuel... Quand la conviction change, que la conscience change avec elle, mais pas avant... Et voyez à quelle diatribe m'a conduit un sujet que jaborde rarement, mais sur lequel jai longuement réfléchi... Et, entre parenthèses, ma conversation, quand elle sanime, est très peu féconde en "bons mots", comme le voudrait ma lèvre inférieure. Mais elle produit assez volontiers l'argument; et je me fais, partout où je passe, une renommée de discuteur. Je vous en ai servi, sans y penser, un échantillon... Veuillez me le pardonner, et me croire

Votre bien cordialement dévoué

Louis Dantin

P.S. J'avais bien reçu la critique de "Lecteur" sur votre plaquette: je vous en reparlerai une autre fois.

N.D.L.R. Cette lettre de Louis Dantin a été reproduite telle quelle. Nous avons respecté l'orthographe et la ponctuation du document original. 